\title{
TRANSATLANTIC AFFILIATIONS OF SCIENTIFIC COLLABORATION IN STRATEGIC MANAGEMENT: A QUARTER-CENTURY OF BIBLIOMETRIC EVIDENCE
}

\author{
Oskar $\mathrm{KOSCH}^{(\mathbb{D})}$, Marek SZARUCKI ${ }^{*}$ \\ Strategic Analysis Department, Cracow University of Economics, Krakow, Poland
}

Received 16 November 2019; accepted 19 March 2020

\begin{abstract}
The main objective of the paper is to identify and explore patterns and dynamics of transatlantic scientific collaboration in the field of strategic management between the United States (US) and European countries (EUC) during the last quarter century. Scholarly connections between countries, cities and institutions on the basis of co-author affiliations were analysed to determine the knowledge flow from a geographical perspective. This is the first time international scientific collaboration between researchers in the field of strategic management has been studied to such an extent. We employed all sources of relevant data from the Web of Science and Scopus databases and explored 453 results. Utilizing a bibliometric analysis, our study offers a comprehensive and up-todate identification and assessment of the current situation and dynamics of transatlantic scientific collaboration. The obtained results confirm the dominant role of the US in this type of collaboration. Also, the dominant role of several clusters in terms of collaboration, both on country and institution levels can also be observed. The study confirms the weaker position of Eastern and Central Europe countries in this collaboration and provides some recommendations to increase this type of knowledge exchange in the future.
\end{abstract}

Keywords: strategic management, transatlantic scientific collaboration, bibliometrics, USA, Europe.

JEL Classification: D83, D85, L10, M10, M19.

\section{Introduction}

Strategic management, as a relatively young field rooted in management sciences, has been constantly developing and growing since its inception during the twentieth century. Some evidence collected from the first essential publications from the US show that as an academic discipline it originated in the beginning of the 1960s and commenced with the pioneering works of Chandler (1962), Ansoff (1965) and Andrews (1971) while others have argued that its formal birth is dated to the late 1970s after being suddenly relabelled and reconceptualised

\footnotetext{
${ }^{\star}$ Corresponding author. E-mail: szaruckm@uek.krakow.pl
} 
from the term "business policy" in 1979 (Schendel \& Hofer, 1979). Since then scientists from different countries worldwide have constantly contributed to the growth of knowledge in this field. The growth of knowledge in strategic management has been thoroughly explored in recent years, portraying its historical development, presenting its intellectual composition, and evaluating its strengths and drawbacks (Boyd et al., 2005a, 2005b; Ferreira et al., 2016; Furrer et al., 2008; Nerur et al., 2008; Ramos-Rodríguez \& Ruíz-Navarro, 2004; L. Tan \& Ding, 2015). Moreover, some authors have conducted comprehensive summaries of the intellectual structure of strategic management research in specific industries, for example the hospitality industry (Koseoglu et al., 2019a, 2019b).

Starting from the second half of the twentieth century there has been a growing tendency of collaboration between scientists and the production of joint publications. In contrast to the previous trend of a dominant ratio of solo authors of scientific texts, the tendency of co-authored scientific texts, especially in natural sciences (Hudson, 1996) has increased significantly. Studies exploring the tendency of collaboration among scientists have proved that in the majority of scientific disciplines there is an increasing trend to co-author on-going research (Cronin et al., 2003; Moody, 2004). As a consequence of this trend, there has been a growing interest in investigating this phenomenon also in social sciences and their sub-disciplines or fields, such as for management studies (Acedo et al., 2006), where the authors discovered that the major positions within the authorship network are taken by US authors from several esteemed universities who usually possess prominent positions in professional scientific associations as well as the fact that many are editors of journals.

A growing number of scholars have engaged solely in knowledge development, while collaboration within their own countries and internationally has played a big part in the field's evolution. The issue of the trend of growing collaboration has not been analysed thoroughly and the question of collaboration between North America and Europe is still underdeveloped. This study explores the structure of the North-American and European scientific networks and their resultant productivity influencing the growth of knowledge of the field. The main objective was to identify and explore the specific patterns and trends in transatlantic scientific collaboration in the field of strategic management between the US and European countries (EUC) during the last quarter century.

To achieve this objective, scientific connections among the scholars of strategy distributed in different countries and cities on two continents were explored. Based on the affiliation of articles' co-authors the attempt was to identify the knowledge flow between the US and Europe. The transatlantic scientific collaboration between scholars in the field of strategic management has not been examined to such an extent until now. Utilizing methods of bibliometric analysis, descriptive statistics, heatmaps and social networks analysis, this study covers all sources of appropriate publications from the Scopus and Web of Science databases. The study provides a comprehensive and up-to-date identification and assessment of the trends of international scientific collaboration in the field of strategic management between the US and European countries.

Following this introduction, the current article is structured as follows: A literature review examines the evolution of the strategic management field, paying specific attention to studies on scientific collaboration and its effects on the field's development. The study then describes 
bibliometric methods applied to study the co-authored articles. The next section presents the results of the scholars' collaboration analysis and discussion. Finally, the article provides conclusions, research limitations and suggestions for future research.

\section{Literature review}

This article is based on a set of studies exploring the strategic management field with a main focus on contributions that have researched the development of different topics within the field, and specifically scientific collaboration and its importance for the field's evolution. Scientific collaboration can be perceived as a social process which is determined by various reasons for researchers to work together (Katz, 1994). Since the main research object is the results of scientific collaboration in the form of scientific publications, two types of such documents were analysed: those co-authored nationally and those co-authored internationally. A nationally co-authored scientific document is one that has more than one author from the same country, and a publication is considered internationally co-authored, when two or more of the authors originate from at least two different countries (Wagner \& Leydesdorff, 2005a). International scientific collaboration (or synonymously "co-operation") is also known as a communication network with its own peculiarities and internal dynamics compared to those rooted in national environments (Wagner \& Leydesdorff, 2005b). There are various reasons to collaborate with other researchers also on the international level explained by different theories, e.g. self-efficacy theory (Bock et al., 2005; Stone, 1974; C. N. L. Tan, 2016) or institutional theory (Mosey et al., 2012), although this aspect is beyond the main objective of this research. Nevertheless, international scientific collaboration requires more attention from researchers to uncover its dynamics and impact on the development of various academic disciplines. To begin, main developments of strategic management theory will be discussed.

There has been a growing interest among scholars of exploring different issues and topics regarding the field of strategic management over the last several decades. Perceiving an academic field as a socially created entity (Kuhn, 1996), means that it has socially discussed borders and only remains if a significant number of scientists admit to its existence and embrace a mutual idea of its fundamental sense (Astley, 1985). Bibliometric analysis serves an important role in identification of main topics in strategic management research and supports the idea of its widening scope. There have been several more or less direct scientific attempts to discover the shape of the analysed field of knowledge to date. According to Ramos-Rodríguez and Ruíz-Navarro (2004), during the early phase of the field's development, in comparison to journal papers, books had a greater impact, specifically those of Alfred Chandler, Igor Ansoff, Kenneth Andrews and later on Michael Porter. Another study utilising an author co-citation analysis conducted by Nerur et al. (2008) described the subfields and their evolution during the period of 1980-2000 which constituted the intellectual structure of strategic management, as well as provided insight on the impact of individual scholars and chronological changes affecting their impact. Ferreira et al. (2016) conducted the most comprehensive bibliometric analysis of strategic management research based on a longitudinal co-citations' analysis that addressed the attributes and key topics of the strategic 
management field between 1971 and 2014. The researchers identified six subfields that composed the intellectual structure and explored their reciprocal connections.

As far as strategic management is concerned, there is an increasingly large number of social communities made up of strategy scholars, that actively attend prominent organizations and their annual conferences including the Strategic Management Society, the Academy of Management with its Strategic Management Division and the European Academy of Management with its Strategic Management Group. The mentioned academic communities attract strategy scholars worldwide and have a crucial impact on the field's development. Also, of importance for the field's development is national and international scientific collaboration measured in number of co-authored articles.

It is important to mention the Strategic Management Journal (SMJ), launched in 1980, which is now approaching its fortieth anniversary, and as one of the most prominent and influential sources of publishing research results of strategic management is often considered an object for analysis itself. Phelan, Ferreira, and Salvador (2002) explored changes in the SMJ publication over the first twenty years according to diversity and content of the published articles. A more recent study was conducted by Tan and Ding (2015). The authors utilized a scientometric analysis of the articles, limiting their research to those published in the SMJ between 2001 and 2012, and shed some light on the frontiers and progress of the research of strategic management during the beginning of the twenty-first century. Another more recent study by Nerur, Rasheed, and Pandey (2016) concentrated on an analysis of the knowledge flows within SMJ during the period of 1980-2009 and focused on citations' analysis and confirming the importance of the journal for both sourcing and accumulating knowledge. In the meantime, Ronda-Pupo and Guerras-Martín (2010) explored the dynamics of the scientific community network by researching knowledge creation and dissemination through the Strategic Management Journal from 1980 to 2009. Their results highlight the evolution of the contributor countries' place in the scientific papers published in the SMJ and differentiated three phases of development: formation/incorporation, consolidation/dissemination, and expansion/transformation. The topic of scientific collaboration in the strategic management field was continued by Koseoglu (2016a) who concentrated on the evolution of author collaboration and the co-authorship network by utilising evaluative and relational bibliometric methods.

In spite of the importance of the SMJ for publishing research on strategy, it still does not provide the entire picture of multiple sources or scientific works on strategic management. Thus, there is a need to increase the scope and deepen the analysis of the field's research to better comprehend its boundaries as well as past, present and future trends related to scientific collaboration and its impact on theory development. In regard to these trends, Laband and Tollison (2000) have argued the incidence of co-authorship (i.e. the proportion of articles with multiple authors) should be separated from the extent of co-authorship (i.e. the average number of authors of co-authored articles).

Based on a comprehensive analysis conducted by Ronda-Pupo and Guerras-Martín (2010) on the development of the scientific community of the discipline, cooperation within strategic management among authors from different countries has increased continually. In the beginning it included authors from the lead country that collaborated with researchers 
from countries situated on the outside edge or peripheries of the network. Later the network was expanded by adding researchers from new countries representing their academic institutions and integrating them into the scientific community studying the field of strategic management. As a field that has ambitions to build multidisciplinary, international and multilingual relations of scientists benefiting this type of collaboration, this is a very important trend for strategic management. It is obvious that due to its worldwide geographical dispersion, this scientific community faces various challenges such as linguistic, national, cultural and regional boundaries that split fairly autonomous academic communities. As a consequence, this may lead to "parochialism" and its consequences to the science (March, 2005), especially when some original theoretical concepts built by local researchers' communities are preserved, however, due to insularism their knowledge is not diffused abroad and therefore limits a comprehensive development of the science. Exchange of knowledge between academic sub-communities is perceived as an antidote to such negative consequences (Daft \& Lewin, 2008). Such models of knowledge flows must be analysed within the strategic management field utilising a rigorous methodology.

A large portion of all research considered as North American (i.e. authorship, editorship and citations) is biased in a geographically provincial way in both the North American and the European journals (March, 2005). From the historical perspective of the strategic management field's evolution, the dominant role of international and intra-national collaboration is traditionally rooted in the US. Nevertheless, it is not clear how US based scientific collaboration with various European countries contributes to the growth of knowledge of strategic management. There is a gap in this area and only a few limited studies usually tied to publications in the Strategic Management Journal. There is a need to increase the scope of sources of scientific publications within the field of strategic management in order to confirm the trend discovered by Ronda-Pupo and Guerras-Martín (2010), and to discover other specifics of transatlantic cooperation with specific parts of Europe. Thus, the research questions are: What are specific patterns and trends of transatlantic cooperation between the US and European countries. And how does the inclusion of new countries in the network's structure impact the shape of the model of transatlantic collaboration the field? What is the level of the inclusion of two groups of countries: Western, and Central and Eastern European (CEE)?

In order to achieve the research objective, the study concentrated on the analysis of scientific connections between countries, cities and institutions in Europe and the US. Spatial data analysis was applied on the basis of co-authorship to determine the knowledge flow from the geographical perspective. Its original contribution resulted in presenting a unique pattern of the North-American and European scientific networks and their effects in terms of joint publications contributing to the development of the strategic management field.

\section{Methodology}

For methodological reasons there is a distinction between the institutions where the authors of publications were employed and their affiliations based on the current employment locations of the authors (Combes \& Linnemer, 2003; Corsatea, 2010). Usually every publication is assigned to the institution (university or research centre) where the co-authors work. Here 
affiliation is perceived as one consisting of three basic elements - the name of the institution, the city of the institution and the country. Each of these elements is taken as a separate level of analysis, beginning with the broadest one (countries) through cities, to finally the institutions.

The study involved broad data gathering and following complex preparation. This stage of the research was crucial, as it contributed most to the outcomes by the presence of the "garbage in garbage out" principle - poor data will lead to poor results. Also, a clear borderline between data gathering and preparation and further analysis had to be drawn to ensure that the analysis process would not be biased towards some publications studied. After data gathering and preparation, the analysis was performed; all steps leading to the results are explained in the following sub-sections.

\subsection{Documents collection}

Due to the known issue of a single database being unable to deliver comprehensive coverage (Bramer et al., 2017), the chosen data sources were Web of Science (WoS) and Scopus bibliographic databases. The query was constructed to search for all European countries' documents (the type of the document was not specified, because this study aimed to reveal collaboration patterns, not the content and type of the documents, which is present even in conference proceedings) for the years 1993-2017. European countries are here understood as these having even a part of the territory in the agreed upon geographic borders of Europe (Windley et al., 2019) or claimed by the European Union to be such (European Union, n.d.). This timespan was chosen because of the last major border changes (Czechoslovakia divided into Czech and Slovak republics). The year 2017 was selected as bibliographic databases may note some lag between publication and the records being entered, and two years were viewed as sufficient. The queries were aimed to be identical, but some minor differences in the databases had to be addressed (such as the WoS use of "Russia" and Scopus' use of "Russian Federation"). Coverage of WoS was 3,634 documents and Scopus retrieved 4,338 documents. Exclusion of grey literature was intended, as the further data analysis relied on the consistency of the collection that could not be ensured by Google's relevance algorithm which provides thousands of results without satisfying some Boolean requirements. The two sources were then combined and deduplicated using a bibliometrix package (Aria \& Cuccurullo, 2017).

\subsection{Documents preparation}

Data preparation that was performed later included unification of the styles of both bibliographic databases, e.g. different affiliations format, countries extraction and cities extraction (term "city" is used here interchangeably with "town"). These actions were performed using relevant tools, such as regular expressions (Wickham, 2018) or string similarity measures (van der Loo, 2014). For example, of 1,579 affiliation entries found in US co-authored records, 1,423 were unique. But subsequent extraction of affiliation title (e.g. Bocconi University) and pasting it with the extracted city and country (thus deleting faculty, departments, etc.) narrowed this number to 945 unique affiliations. Then, string similarity measures were 
constructed using the longest common substring method, and the names that were similar in more than 95\% were merged (e.g. WoS "University California" vs Scopus "University of California"). Subsequently, the frequency table was manually checked for remaining differences, such as Copenhagen Business School, that is listed as both Frederiksberg and Copenhagen, wasn't merged automatically. These actions formed a collection of 854 unique affiliations. As shown, the data preparation contributed vastly to further analysis and required much effort to ensure appropriate methodological rigour. The last step consisted of geocoding the affiliations, to provide latitude and longitude needed to plot the heatmap - this was performed using regular expressions of cities and countries combined, with preference given to the larger city, in case of the same name and country.

\subsection{Documents inclusion}

When data was prepared, the records were checked if they were eligible for inclusion in the corpus of strategic management related papers. Because the phrase "strategic management" may appear in different contexts not related to the discussed field of science, the works were check against four criteria, of which at least two had to be satisfied:

- the document either cites or is cited by others in the collection (local citations),

- the document mentions a keyword (or was assigned a keyword by the database creators) that appears more than once in the collection,

- the source of the document appeared more than once in the collection,

- the author or one of the co-authors appears more than once in the collection.

Out of 6,450 unique records, 5,237 were found to be relevant to the strategic management field of science. The last step of inclusion of documents was to filter out all works, that were not US-Europe connected; only 461 documents were authored by researchers currently affiliated with both the United States and Europe. The examination of the publication's relevancy by authors revealed 6 documents, that were integrated with each other, and in that way, they were not removed by filter but were deemed irrelevant and were deleted. An additional 2 papers supposedly pointing to the country of Georgia were mistakes in the Scopus database, as Georgia meant the state, and the documents were not an effect of collaboration with European authors. That left 453 papers for analysis. There were 9 researchers that were single authors of documents, but because they were affiliated both in the US and at least one of the European countries, they contributed to affiliation collaboration and were therefore left in the study.

\subsection{Documents analysis}

The study assumed affiliations as units of analysis, and the co-occurrence (co-authorship) on three levels of affiliation field was studied: country level, city level, and institution level. Descriptive statistics (for countries), heatmaps (for cities), and social networks analysis (for institutions) were performed.

The countries descriptive statics used were: 1) frequency of unique countries involved in the document, 2) total number of documents, 3) number of documents for 5-year periods, 4) share in US links, 5) average number of specific country authors per article, 6) average 
share of the authors of the article. The first point assessed the patterns for collaboration in terms of number of countries collaborating within a single document. The measures, 2 and 4 describe the importance of certain countries in the US-EUC collaboration. Point 3 assessed dynamics of collaboration of different countries in a given dataset. Points 5 and 6 showed dominance in a single contribution, as depicted by number and share of authors. The measures of points 2 to 6 were also given as totals, both when calculated per each country separately, hence allowed double counting (but only of European countries) and also aggregated, that excluded double counting.

Regarding the cities, a frequency table was created, to find the places which occurred most frequently, but also to generate a heatmap. The heatmap was constructed with use of the ggplot2 (Wickham, 2016) and maps (Brownrigg, 2018) R packages.

The institutions co-occurrence network and its induced subgraph of the ones that were responsible for more than 4 documents were created using the igraph (Csárdi \& Nepusz, 2006) R package. The construction of networks allowed the use of centrality measures such as degree, strength and normalized betweenness of the nodes. These are well known indicators (Freeman, 2011) and their exact applications are specified in the igraph package manual (Csárdi, 2019). The set of measures that were calculated is as follows: 1) number of unique collaborating institutions (degree), 2) normalized degree, 3 ) the number of all collaborations (weighted degree, strength), 4) betweenness measure that show the importance of connecting institutions, 5) the number of researchers involved in collaboration with the institution, 6) the preference towards one-time collaboration expressed as degree/ strength, 7) the number of unconnected cluster nodes, and 8) the number of second order neighbours.

Whenever distance was needed to calculate metrics, the inverted edge weight was used. Additionally, the number of documents was also calculated. The igraph adaptation of Louvain clustering (Blondel et al., 2008), and linear regression were applied to detect clusters and trends over the entire studied period. The interpretation of institutions' network was aided by the VOSviewer (van Eck \& Waltman, 2010) as a graphical interface for data exported in Pajek format. Furthermore, linear regression was used to capture the trend of identified clusters output.

\section{Results and discussion}

\subsection{Countries}

In terms of number of countries involved, the collaboration of US-EUC was seen mainly in the direct aspect, with optional non-EUC countries involved (see Table 1). It contributes to the observation that the EUC either choose European collaboration or collaboration with the US. The proportion of all countries is very close to the results provided by Koseoglu (2016a, p. 158), when filtered out of single documents and calculated for relative values, thus supporting the findings presented there.

Most of the papers (62.69\%) were created in direct collaboration between the US and one of the European countries. 
Table 1. Documents quantity by number of countries involved (source: own study based on Web of Science and Scopus)

\begin{tabular}{|l|c|c|c|c|c|c|c|}
\hline \multirow{3}{*}{ Countries included } & \multicolumn{7}{|c|}{ The number of countries } \\
\cline { 2 - 8 } & 2 & 3 & 4 & 5 & 6 & 7 & 9 \\
\hline \multirow{2}{*}{ ALL } & 284 & 132 & 24 & 9 & 3 & 0 & 1 \\
& $62.69 \%$ & $29.14 \%$ & $5.30 \%$ & $1.99 \%$ & $0.66 \%$ & $0 \%$ & $0.22 \%$ \\
\hline \multirow{2}{*}{ US \& EUC only } & 342 & 93 & 13 & 4 & 0 & 1 & 0 \\
& $75.50 \%$ & $20.53 \%$ & $2.87 \%$ & $0.88 \%$ & $0 \%$ & $0.22 \%$ & $0 \%$ \\
\hline
\end{tabular}

The countries network that was created consisted of a total of 54 countries. Among them, 30 European countries (EUC) were found, and all other countries - apart from the United States (US) - were removed, and such US-EUC network was considered and further depicted in Table 2, with US being omitted because of its presence in each of the documents. The 5 EUC countries that collaborated most with the US were: United Kingdom (106, 18.03\%), Germany (67, 11.39\%), Italy (52, 8.84\%), France (50, 8.50\%), and Spain (43, 7.31\%). The strong position of UK may not only be the result of the language, but also the Anglo-American bipolar model (Gui et al., 2019). It is worth noting the low level of collaboration between the US and Central and Eastern Europe (the former Soviet Bloc). This is in line with the observation of traditional Russian-CEE links in social sciences (Marshakova-Shaikevich, 2010 , p. 62) that are rooted in the $20^{\text {th }}$ century. Even the discussed increase in overall scientific collaboration between older and newer European Union members (Makkonen \& Mitze, 2016) doesn't seem to affect this state. The average number of authors shows the extent of the authors involvement in the research, on average. The variance of this value is probably a result of too small a number of publications, thus allowing the values to take extreme positions. This indicator for the entire collection is 3.21 .

Table 2. United States - European countries collaboration overview (source: own study based on Web of Science and Scopus)

\begin{tabular}{|l|c|c|c|c|c|c|c|c|c|}
\hline $\begin{array}{c}\text { Country of affiliation of at } \\
\text { least one author }\end{array}$ & $N_{T}$ & $S_{S}$ & $A_{C}$ & $A_{S}$ & $N_{1}$ & $N_{2}$ & $N_{3}$ & $N_{4}$ & $N_{5}$ \\
\hline Albania & 1 & $0.17 \%$ & 2.00 & $50.00 \%$ & 0 & 0 & 0 & 0 & 1 \\
\hline Austria & 12 & $2.04 \%$ & 4.33 & $37.34 \%$ & 0 & 1 & 1 & 4 & 6 \\
\hline Belgium & 17 & $2.89 \%$ & 2.82 & $34.07 \%$ & 0 & 1 & 1 & 6 & 9 \\
\hline Bulgaria & 2 & $0.34 \%$ & 4.00 & $33.33 \%$ & 0 & 0 & 0 & 2 & 0 \\
\hline Croatia & 2 & $0.34 \%$ & 4.00 & $20.83 \%$ & 0 & 0 & 0 & 0 & 2 \\
\hline Cyprus & 5 & $0.85 \%$ & 2.80 & $31.33 \%$ & 0 & 0 & 1 & 1 & 3 \\
\hline Czech Republic & 2 & $0.34 \%$ & 2.00 & $41.67 \%$ & 0 & 0 & 0 & 1 & 1 \\
\hline Denmark & 21 & $3.57 \%$ & 3.38 & $36.64 \%$ & 0 & 0 & 3 & 9 & 9 \\
\hline Finland & 24 & $4.08 \%$ & 4.12 & $38.59 \%$ & 0 & 2 & 5 & 6 & 11 \\
\hline France & 50 & $8.50 \%$ & 3.16 & $34.82 \%$ & 0 & 5 & 3 & 14 & 28 \\
\hline Germany & 67 & $11.39 \%$ & 3.78 & $41.40 \%$ & 0 & 1 & 4 & 24 & 38 \\
\hline
\end{tabular}


End of Table 2

\begin{tabular}{|l|c|c|c|c|c|c|c|c|c|}
\hline $\begin{array}{l}\text { Country of affiliation of at } \\
\text { least one author }\end{array}$ & $N_{T}$ & $S_{S}$ & $A_{C}$ & $A_{S}$ & $N_{1}$ & $N_{2}$ & $N_{3}$ & $N_{4}$ & $N_{5}$ \\
\hline Greece & 5 & $0.85 \%$ & 4.60 & $40.33 \%$ & 0 & 2 & 2 & 0 & 1 \\
\hline Hungary & 3 & $0.51 \%$ & 7.00 & $16.67 \%$ & 0 & 1 & 0 & 0 & 2 \\
\hline Ireland & 10 & $1.70 \%$ & 4.20 & $40.60 \%$ & 0 & 0 & 0 & 4 & 6 \\
\hline Italy & 52 & $8.84 \%$ & 3.42 & $42.07 \%$ & 0 & 2 & 4 & 18 & 28 \\
\hline Latvia & 1 & $0.17 \%$ & 3.00 & $33.33 \%$ & 0 & 0 & 0 & 1 & 0 \\
\hline Liechtenstein & 4 & $0.68 \%$ & 4.50 & $26.67 \%$ & 0 & 0 & 0 & 0 & 4 \\
\hline Lithuania & 1 & $0.17 \%$ & 5.00 & $25.00 \%$ & 0 & 0 & 0 & 0 & 1 \\
\hline Monaco & 2 & $0.34 \%$ & 4.50 & $25.00 \%$ & 0 & 0 & 0 & 0 & 2 \\
\hline Netherlands & 40 & $6.80 \%$ & 3.98 & $36.24 \%$ & 0 & 5 & 6 & 11 & 18 \\
\hline Norway & 10 & $1.70 \%$ & 4.10 & $30.33 \%$ & 1 & 1 & 1 & 2 & 5 \\
\hline Poland & 6 & $1.02 \%$ & 2.50 & $41.67 \%$ & 0 & 0 & 2 & 0 & 4 \\
\hline Portugal & 8 & $1.36 \%$ & 4.00 & $37.59 \%$ & 0 & 1 & 1 & 0 & 6 \\
\hline Russia & 4 & $0.68 \%$ & 2.75 & $45.83 \%$ & 0 & 2 & 0 & 1 & 1 \\
\hline Slovenia & 6 & $1.02 \%$ & 2.67 & $44.44 \%$ & 0 & 1 & 1 & 1 & 3 \\
\hline Spain & 43 & $7.31 \%$ & 3.05 & $39.69 \%$ & 0 & 0 & 6 & 9 & 28 \\
\hline Sweden & 22 & $3.74 \%$ & 3.59 & $37.71 \%$ & 0 & 0 & 1 & 11 & 10 \\
\hline Switzerland & 38 & $6.46 \%$ & 3.05 & $38.89 \%$ & 0 & 2 & 1 & 14 & 21 \\
\hline Turkey & 24 & $4.08 \%$ & 3.33 & $42.99 \%$ & 0 & 1 & 4 & 7 & 12 \\
\hline United Kingdom & 106 & $18.03 \%$ & 3.39 & $34.37 \%$ & 3 & 9 & 18 & 29 & 47 \\
\hline $\begin{array}{l}\text { Total (EUC multi } \\
\text { counting) }\end{array}$ & 588 & - & - & - & 4 & 37 & 65 & 175 & 307 \\
\hline Total (single counting) & 453 & - & - & - & 4 & 31 & 59 & 133 & 226 \\
\hline
\end{tabular}

Abbreviations: $N_{T}$ - Documents with US in total, $S_{S}$ - Share in unique US-EUC links (strength share), $A_{C}$ - Average number of country authors, $A_{S}$ - Average share of country authors in the document, $N_{1}$ - documents in the first timespan: 1993-1997, $N_{2}$ - documents in the second timespan: 19982002, $N_{3}$ - documents in the third timespan: 2003-2007, $N_{4}$ - documents in the fourth timespan: 2008-2012, $N_{5}$ - documents in the fifth timespan: 2013-2017.

The next indicator used was the average share of countries' authors in a co-authored document. It shows the amount of exposure that authors affiliated with a certain country get. This situation should be considered from two points of view: on one hand, lower values mean that the presence of the country may be less visible, but on the other hand, higher values may suggest that it is a more demanding task for Europeans to enter such US-EUC collaboration. The United States ratio was on the level of $45.96 \%$, compared to a mean of about $36.30 \%$ reveals the preference of United States researchers to take the lead role in the research. At the same time, the United Kingdom, the country that collaborates with US the most, holds a value below average, revealing their preference to take part in the process, but only to a limited extent.

As far as dynamics are concerned, overall growth of the field is noted in all timespans that were studied, and supports the observation of increasing US-EUC collaboration (Koseoglu, 
2016b, p. 219). Only Norway and the United Kingdom appeared in all periods, showing the preference for stable cooperation, and validating the database query timespan, by the fact, that not much collaboration took place before 1993. Especially the UK was an early adopter of the US-EUC collaboration. The 5 countries that showed the highest growth (above 100\%) in the last period are: Spain (211\%), Cyprus (200\%), Slovenia (200\%), Norway (150\%), France (100\%). In case of Cyprus, Slovenia and Norway this increase was probably the result of low collaboration values in previous periods, which caused such extreme values. But the cases of Spain and France are notable, as this increase may continue, and therefore significantly change the US-EUC collaboration structure, which is currently most represented by the United Kingdom and Germany - this supports the trend of transition from core-periphery to a multi-centric model of world science (Gui et al., 2019). The intense growth of Turkey-US collaboration (Aytac, 2010, p. 3) that was once pointed out seems not to be the case in SM.

\subsection{Cities}

The spatial realm is not only represented by countries, but also by cities of affiliation. The heatmap of US-EUC collaboration is depicted in Figure 1. The centre of collaboration lies throughout the north-east coast of US and in the United Kingdom-Netherlands-Germany-Switzerland-Italy axis. The most productive city is London (27), followed by Philadelphia, Atlanta and New York City (23), Milan (21), Washington DC (21), Boston (21), Bloomington (19), Barcelona (18), and Lausanne (15).

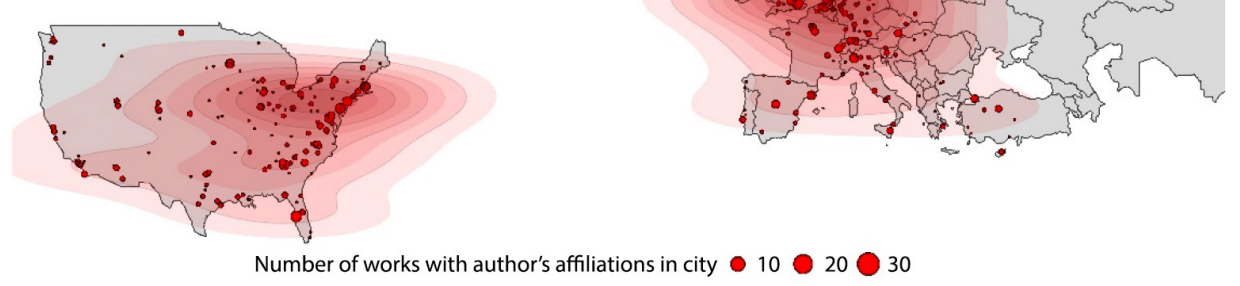

Figure 1. The heatmap of cities (weighted by the number of documents) present in US-EUC documents (source: own study based on Web of Science and Scopus)

It is clear that while there do exist peripheral locations that maintain a high number of publications (e.g. Barcelona) the US-EUC collaboration is scarce outside the core, and sharp delimitation is seen, especially for the former "Eastern Bloc" countries of Central and Eastern Europe (CEE) as depicted by OECD (Organisation for Economic Co-operation and Development, 2001) with an extension of Russia. The possible barriers for scientific collaboration tend to have been sustained over time in the studied region. A relatively low level of US-EUC collaboration was also observed in the Nordic countries. Overall, the parity of US-EUC was enforced by the search strategy and document inclusion, but it should be noted that the 
cities found in this research are responsible for the scientific output, according to Csomós (2017). The heatmap spatial distribution of collaboration centres is a unique attempt of the authors. To the best of our best knowledge, there is currently no other research to compare the results against.

\subsection{Institutions}

The documents collection consisted of published papers connected to 854 institutions, of which 219 appeared more than once. Those which were responsible for the most documents were presented in Table 3. The number of institutions that were responsible for more than 4 documents is 56 , the biggest component (53 institutions) forms 5 clusters (with modularity of 0.603$)$ :

- Brigham Young University, US \& College of Management of Technology, CH \& Copenhagen Business School, DK \& ESADE Business School, ES \& IESE Business School, ES \& INSEAD, FR \& Northeastern University, US \& Ohio State University, US \& Temple University, US \& The University of Warwick, UK \& University of Illinois, US \& University of Minnesota, US \& University Penn, US \& University South Carolina, US \& University Virginia, US;

- Erasmus University, NL \& Florida State University, US \& Indiana University, US \& Jonkoping Int Business School, SE \& Syracuse University, US \& Texas A\&M University, US \& Texas Christian University, US \& The University of Utah, US \& University Cyprus, CY \& University of Calgary, CA \& University of Cambridge, UK \& University of Catania, IT \& University of Oxford, UK \& University of Saint Gallen, CH \& University of Zurich, CH \& Vienna University Econ \& Business Adm, AT;

- Bocconi University, IT \& Duke University, US \& London Business School, UK \& Tilburg University, NL \& Tuck School of Business, US \& University of North Carolina, US \& University of Toronto, US;

- Kennesaw State University, US \& University Magdeburg, DE \& Hamburg University of Technology, DE \& Georgia State University, US;

- Arizona State University, US \& Auburn University, US \& Case Western Reserve University, US \& George Washington University, US \& University College Dublin, IE \& University Connecticut, US \& University of Denver, US \& University of Ghent, BE \& University of Ljubljana, SI \& Whu Otto Beisheim Grad School Management, DE.

Of these clusters, the highest growth trend as far as number of publications is the second. This is also due to the fact that it is the largest cluster and probably most accessible to new institutions. The dynamics of the above mentioned clusters are depicted in Figure 2 - these clusters are formed based on the entire studied period, and are not constant in time, so this is rather a chart of production of institutions that will eventually form such clusters. This is connected to the size of the cluster, but also points out the possibility of some clusters' members becoming more prominent over time, such as the fact that there may be institutions that outperform currently more prominent ones. Assuming that by sharing the same neighbours, nodes are more likely to establish collaboration (that is, do so within the cluster) and may do so easier as some institutions hold more potential to expand in terms of degree of collaboration, such as the University of Cambridge, that still has 14 cluster members to reach out (see Table 3, the $U_{C}$ column). Institutions may also exercise their ability to reach 
second-order neighbours - that is institutions that are connected to their neighbours but not to themselves. This may not be easy to achieve if their collaboration partner benefits from the existence of forbidden triads, but generally, networks study shows that it may be the source of fruitful collaboration (Vedres, 2017).

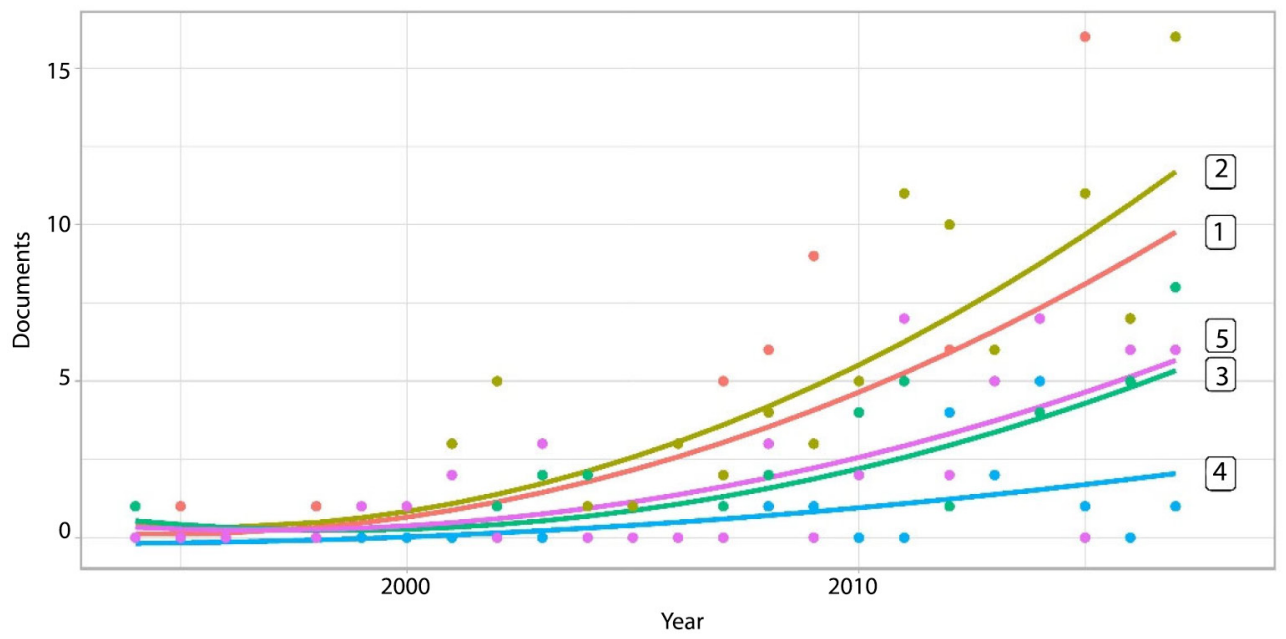

Figure 2. The dynamics of clusters documents output of the most productive collaborating institutions (source: own study based on Web of Science and Scopus)

This shows the most important institutions that link the United States with Europe. Most of the institutions listed by Koseoglu (2016b, pp. 215-216) were also found in this list, although the ranks are rarely preserved - for example, Indiana University that ranks first in this study in terms of degree, in the dataset studied by Koseoglu (2016b) was listed as fifth, and third in terms of betweenness. The list differs even more, when compared to the most influential institutions in the entire business \& economics area (Merigó et al., 2016, p. 406), for which only 6 common institutions were found, and all from the US. This commits to the belief that top institutions in the case of European collaboration in SM are different, and the importance of the entity may have local character and may be considered of different value by various researchers. Also, betweenness that shows the ability of the node to control information flows puts Indiana University in the comfortable situation of being the most influential institution in the studied setting. The most important European institutions that possess the ability to shape US-EUC collaboration are Bocconi University, Copenhagen Business School and Erasmus University. That being stated, it should be noted that out of the 20 listed institutions, 10 are located in United States, giving a sense that Europe only can hold a parity with the US if it is consolidated as a single entity, but not as a set of dispersed countries and institutions.

Other examples are: HEC Paris that was responsible for only 6 documents and didn't make it to the top 20 institutions, or Copenhagen Business School, that barely made the list in comparison to Koseoglu's research (2016b), whereas here it was ranked as the third most influential collaborator. What should be considered as an outlier, is Bocconi University's attitude towards exploiting existing connections instead of forming new ones - but 
Table 3. 20 institutions with the highest number of documents and their properties (source: own study based on Web of Science and Scopus)

\begin{tabular}{|c|c|c|c|c|c|c|c|c|c|}
\hline Name & $D$ & $D_{N}$ & $S$ & $B_{C}$ & $N$ & $R_{I}$ & $P_{N C}$ & $U_{C}$ & $E_{2}$ \\
\hline $\begin{array}{l}\text { Indiana University, Bloomington, } \\
\text { United States }\end{array}$ & 41 & 0.05 & 50 & 0.13 & 19 & 46 & 0.82 & 5 & 24 \\
\hline Bocconi University, Milan, Italy & 20 & 0.02 & 38 & 0.05 & 16 & 25 & 0.53 & 1 & 10 \\
\hline $\begin{array}{l}\text { Copenhagen Business School, } \\
\text { Copenhagen, Denmark }\end{array}$ & 23 & 0.03 & 25 & 0.06 & 13 & 28 & 0.92 & 7 & 17 \\
\hline $\begin{array}{l}\text { Texas Christian University, } \\
\text { Fort Worth, United States }\end{array}$ & 28 & 0.03 & 32 & 0.06 & 12 & 27 & 0.88 & 9 & 21 \\
\hline $\begin{array}{l}\text { Erasmus University, Rotterdam, } \\
\text { Netherlands }\end{array}$ & 23 & 0.03 & 24 & 0.04 & 11 & 27 & 0.96 & 11 & 31 \\
\hline $\begin{array}{l}\text { Texas A\&M University, Atlanta, } \\
\text { United States }\end{array}$ & 22 & 0.03 & 28 & 0.08 & 11 & 28 & 0.79 & 10 & 22 \\
\hline $\begin{array}{l}\text { University Penn, Philadelphia, } \\
\text { United States }\end{array}$ & 12 & 0.01 & 15 & 0.03 & 11 & 22 & 0.80 & 10 & 7 \\
\hline $\begin{array}{l}\text { Syracuse University, Syracuse, } \\
\text { United States }\end{array}$ & 21 & 0.03 & 24 & 0.05 & 10 & 29 & 0.86 & 11 & 19 \\
\hline $\begin{array}{l}\text { Duke University, Durham, } \\
\text { United States }\end{array}$ & 19 & 0.02 & 27 & 0.04 & 9 & 25 & 0.70 & 0 & 16 \\
\hline $\begin{array}{l}\text { George Washington University, } \\
\text { Washington Dc, United States }\end{array}$ & 19 & 0.02 & 22 & 0.03 & 9 & 23 & 0.86 & 7 & 13 \\
\hline $\begin{array}{l}\text { Kennesaw State University, Kennesaw, } \\
\text { United States }\end{array}$ & 17 & 0.02 & 27 & 0.01 & 9 & 20 & 0.63 & 0 & 8 \\
\hline $\begin{array}{l}\text { University Of Oxford, Oxford, } \\
\text { United Kingdom }\end{array}$ & 27 & 0.03 & 31 & 0.05 & 9 & 23 & 0.87 & 12 & 19 \\
\hline $\begin{array}{l}\text { Jonkoping Int Business School, } \\
\text { Jonkoping, Sweden }\end{array}$ & 15 & 0.02 & 20 & 0.04 & 8 & 21 & 0.75 & 9 & 21 \\
\hline $\begin{array}{l}\text { London Business School, London, } \\
\text { United Kingdom }\end{array}$ & 21 & 0.03 & 26 & 0.02 & 8 & 19 & 0.81 & 1 & 12 \\
\hline $\begin{array}{l}\text { Tilburg University, Tilburg, } \\
\text { Netherlands }\end{array}$ & 12 & 0.01 & 14 & 0.01 & 8 & 18 & 0.86 & 4 & 7 \\
\hline $\begin{array}{l}\text { University N Carolina, Chapel Hill, } \\
\text { United States }\end{array}$ & 10 & 0.01 & 22 & 0.03 & 8 & 14 & 0.46 & 0 & 9 \\
\hline $\begin{array}{l}\text { University Of Cambridge, Cambridge, } \\
\text { United Kingdom }\end{array}$ & 16 & 0.02 & 20 & 0.01 & 8 & 19 & 0.80 & 14 & 7 \\
\hline University Of Catania, Catania, Italy & 13 & 0.02 & 18 & 0.01 & 8 & 13 & 0.72 & 11 & 20 \\
\hline $\begin{array}{l}\text { University Of Saint Gallen, } \\
\text { Sankt Gallen, Switzerland }\end{array}$ & 21 & 0.03 & 21 & 0.03 & 8 & 23 & 1.00 & 10 & 15 \\
\hline $\begin{array}{l}\text { University Virginia, Charlottesville, } \\
\text { United States }\end{array}$ & 32 & 0.04 & 34 & 0.03 & 8 & 26 & 0.94 & 13 & 11 \\
\hline
\end{tabular}

Abbreviations: $D$ - degree, $D_{N}$ - normalized degree, $S$ - strength, $B_{C}$ - betweenness centrality, $N$ number of documents, $R_{I}$ - researchers involved, $P_{N C}$ - preference for one-time (new) collaboration with other affiliation, $U_{C}$ - unconnected cluster members, $E_{2}$ - second order neighbours (second order ego network with 2 units distance minimum). 
apparently, most of the institutions listed in the top 20 rank positively share the researchers' attitude towards establishing new collaborations. The clustering coefficient was 0.525 and is substantially higher than in the global SM institutions network (Koseoglu, 2016b), which is probably the result of using only internationally collaborated documents, and a relatively smaller network.

Twenty years ago, the EU was said to surpass US in terms of scientific production (Glänzel et al., 1999, pp. 189, 195), although this is not the case in SM, as seen in the institutions' rankings - among the top twenty, the US holds half of them. Even broadening this scope to the entire business \& economics research, the majority of the most influential institutions are based in the United States (Merigó et al., 2016, p. 406). Although, this was not a scope of the research, the US hegemony is seen even more clearly when sources of publications (journals) are considered, as most of them are US-based. Regarding journals, it was observed that in the studied dataset, the Strategic Management Journal was not the most productive in terms of quantity - it holds 41 records and scored second place, whereas, the Strategic Entrepreneurship Journal was the most productive, with 46 publications. This validates the research limitations often pointed out in bibliometrics studies in the field of strategic management, which rely on one or few journals and usually recommend broadening of the data to perform a more comprehensive analysis (Koseoglu, 2016b; Ramos-Rodríguez \& Ruíz-Navarro, 2004; L. Tan \& Ding, 2015; White et al., 2016).

However, as far as the global context is concerned, the prevailing part of top institutions were distributed in the US (Koseoglu, 2016b). This study observed a rapid increase in some countries collaboration and that combined with the changing of the worlds' science model to tri-polar gives an opportunity for the current peripheral or semi-peripheral institutions to hold a high share in European science output and to become new centres for strategic management research.

\section{Conclusions}

The present study contributes to existing research and is the first comprehensive study to analyse scientific collaboration in the field of strategic management between the US and European countries in the last twenty five years by utilising co-authors' affiliations in scientific journals as an indicator. The study has presented a steady growth in the number of US-Europe-affiliated published papers. The patterns of this collaboration were portrayed by country, city and institution of the affiliated co-authors.

The findings have brought forth several important theoretical and practical contributions. First, the most influential countries, cities and institutions in terms of dissemination of transatlantic knowledge of strategic management can be perceived as current and future leaders in developing this kind of knowledge exchange and field's development. The dominant role of the US regarding knowledge development and its transfer in strategic management internationally is obvious. Second, the observed countries perceived as lagging behind in terms of transatlantic collaboration in strategic management are mostly those belonging to the former post-soviet bloc including countries of Eastern and Central Europe. For authors from those countries with a lower score in collaboration it would be beneficial for them to begin 
co-operation with more prosperous colleagues from appropriate European institutions. The information regarding clusters of collaborating institutions within Europe also brings valuable insights related to planning future activity aimed at improving international scientific collaboration. Third, national institutions that support scientific collaboration and knowledge exchange may integrate those insights into their support strategy to develop transatlantic scientific collaboration.

There are some limitations to this research that were the results of chosen bibliometric methods: 1) no actual nationality or country of origin is known, only affiliation, that may be temporary, 2) it is difficult to assess the actual contribution of an author in the collaboration, since reasons for collaboration may be of a non-meritorious nature, and do not reflect actual share in the document. This may be improved by using weighting on authors order of appearance 3) no other collaboration evidence than co-occurrences in scientific papers was taken into account, 4) networks were created using unique co-occurrence, that is, the collaboration was the same if one or two, three or more authors of a single institution were present. That wasn't the case in the heatmap of cities.

This study represents a starting point to study what factors determine transatlantic scientific collaboration between the US and European countries and how this collaboration influences the research quality of strategic management. Other prospective research avenues include: 1) studying lifecycles of scientific clusters, 2) exploring the factors influencing cluster growth, 3) studying scientific collaboration in the same channel (US-EUC) but for other fields of science, and 4) studying scientific collaboration between Europe and other geographical channels of knowledge exchange, e.g. China or Latin America. Moreover, based on the selected theories (e.g. self-efficacy theory or institutional theory), it would be beneficial to explore the motivational factors to collaborate internationally as well as what determinants could enhance this collaboration in the strategic management field.

\section{Funding}

The research results included in this publication were partly supported by the Polish National Agency for Academic Exchange (NAWA) under grant no. PPN/BEK/2018/1/00429/U/00001 and the financial support provided by the National Science Centre Poland (NCN), grant number 2014/13/B/HS4/03452.

\section{Author contributions}

We have equally contributed to the work.

\section{Disclosure statement}

Authors did not have any competing financial, professional, or personal interests from other parties. 


\section{References}

Acedo, F. J., Barroso, C., Casanueva, C., \& Galán, J. L. (2006). Co-authorship in management and organizational studies: An empirical and network analysis. Journal of Management Studies, 43(5), 957-983. https://doi.org/10.1111/j.1467-6486.2006.00625.x

Andrews, K. R. (1971). The concept of corporate strategy. Dow Jones-Irwin.

Ansoff, H. I. (1965). Corporate strategy. McGraw-Hill.

Aria, M., \& Cuccurullo, C. (2017). bibliometrix: An R-tool for comprehensive science mapping analysis. Journal of Informetrics, 11(4), 959-975. https://doi.org/10.1016/j.joi.2017.08.007

Astley, W. G. (1985). Administrative science as socially constructed truth. Administrative Science Quarterly, 30(4), 497-513. https://doi.org/10.2307/2392694

Aytac, S. (2010). Scientific international collaboration of Turkey, Greece, Poland, and Portugal: A bibliometric analysis. Proceedings of the ASIST Annual Meeting, 47(1), 1-3. https://doi.org/10.1002/meet.14504701305

Blondel, V. D., Guillaume, J.-L., Lambiotte, R., \& Lefebvre, E. (2008). Fast unfolding of communities in large networks. Journal of Statistical Mechanics: Theory and Experiment, $2008(10)$, P10008. https://doi.org/10.1088/1742-5468/2008/10/P10008

Bock, G.-W., Zmud, R. W., Kim, Y.-G. \& Lee, J.-N. (2005). Behavioral Intention formation in knowledge sharing: Examining the Roles of extrinsic motivators, social-psychological forces, and organizational climate. MIS Quarterly, 29(1), 87-111. https://doi.org/10.2307/25148669

Boyd, B. K., Finkelstein, S., \& Gove, S. (2005a). How advanced is the strategy paradigm? The role of particularism and universalism in shaping research outcomes. Strategic Management Journal, 26(9), 841-854. https://doi.org/10.1002/smj.477

Boyd, B. K., Gove, S., \& Hitt, M. A. (2005b, March). Construct measurement in strategic management research: Illusion or reality? Strategic Management Journal, 26(3), 239-257. https://doi.org/10.1002/smj.444

Bramer, W. M., Rethlefsen, M. L., Kleijnen, J., \& Franco, O. H. (2017). Optimal database combinations for literature searches in systematic reviews: A prospective exploratory study. Systematic Reviews, 6, 245. https://doi.org/10.1186/s13643-017-0644-y

Brownrigg, R. (2018). Maps: Draw geographical maps. Retrieved 9 January, 2019 from https://cran.rproject.org $/$ package $=$ maps

Chandler, A. D. (1962). Strategy and structure: Chapters in the history of the American industrial enterprise. MIT Press.

Combes, P.-P., \& Linnemer, L. (2003). Where are the economists who publish? Publication concentration and rankings in Europe based on cumulative publications. Journal of the European Economic Association, 1(6), 1250-1308. https://doi.org/10.1162/154247603322752548

Corsatea, T. D. (2010). Measuring science: Spatial investigation of academic opportunities in Belgium. Papers in Regional Science, 89(2), 373-387. https://doi.org/10.1111/j.1435-5957.2010.00293.x

Cronin, B., Shaw, D., \& La Barre, K. (2003). A cast of thousands: Coauthorship and subauthorship collaboration in the $20^{\text {th }}$ century as manifested in the scholarly journal literature of psychology and philosophy. Journal of the American Society for Information Science and Technology, 54(9), 855-871. https://doi.org/10.1002/asi.10278

Csárdi, G. (2019). Package “igraph”. Retrieved 28 October, 2019 from http://cran.r-project.org/web/ packages/igraph/index.html

Csárdi, G., \& Nepusz, T. (2006). The igraph software package for complex network research. InterJournal, Complex Systems, 1695, 1-9. 
Csomós, G. (2017). Visualising cities' international scientific collaboration: A spatial scientometric approach based on Scopus data. Regional Statistics, 7(1), 225-228. https://doi.org/10.15196/RS0712

Daft, R. L., \& Lewin, A. Y. (2008). Rigor and relevance in organization studies: Idea migration and academic journal evolution. Organization Science, 19(1), 177-183. https://doi.org/10.1287/orsc.1070.0346

European Union. (n.d.). Countries. Retrieved 10 February, 2020 from http://web.archive.org/ web/20200210180853/https://europa.eu/european-union/about-eu/countries_en

Ferreira, J. J. M., Fernandes, C. I., \& Ratten, V. (2016). A co-citation bibliometric analysis of strategic management research. Scientometrics, 109(1), 1-32. https://doi.org/10.1007/s11192-016-2008-0

Freeman, L. C. (2011). The development of social network analysis - with an Emphasis on recent events. In J. Scott \& P. J. Carrington (Eds.), The SAGE Handbook of social network analysis (pp. 2639). SAGE. https://doi.org/10.4135/9781446294413.n3

Furrer, O., Thomas, H., \& Goussevskaia, A. (2008). The structure and evolution of the strategic management field: A content analysis of 26 years of strategic management research. International Journal of Management Reviews, 10(1), 1-23. https://doi.org/10.1111/j.1468-2370.2007.00217.x

Glänzel, W., Schubert, A., \& Czerwon, H.-J. (1999). A bibliometric analysis of international scientific cooperation of the European Union (1985-1995). Scientometrics, 45(2), 185-202. https://doi.org/10.1007/BF02458432

Gui, Q., Liu, C., \& Du, D. (2019). Globalization of science and international scientific collaboration: A network perspective. Geoforum, 105, 1-12. https://doi.org/10.1016/j.geoforum.2019.06.017

Hudson, J. (1996). Trends in multi-authored papers in economics. Journal of Economic Perspectives, 10(3), 153-158. https://doi.org/10.1257/jep.10.3.153

Katz, J. S. (1994). Geographical proximity and scientific collaboration. Scientometrics, 31(1), 31-43. https://doi.org/10.1007/BF02018100

Koseoglu, M. A. (2016a). Growth and structure of authorship and co-authorship network in the strategic management realm: Evidence from the Strategic Management Journal. BRQ Business Research Quarterly, 19(3), 153-170. https://doi.org/10.1016/j.brq.2016.02.001

Koseoglu, M. A. (2016b). Mapping the institutional collaboration network of strategic management research: 1980-2014. Scientometrics, 109(1), 203-226. https://doi.org/10.1007/s11192-016-1894-5

Koseoglu, M. A., Law, R., Okumus, F., Barca, M., \& Dogan, I. C. (2019a). Evolution of strategic management research lines in hospitality and tourism. Journal of Hospitality Marketing and Management, 28(6), 690-710. https://doi.org/10.1080/19368623.2019.1550693

Koseoglu, M. A., Okumus, F., Dogan, I. C., \& Law, R. (2019b). Intellectual structure of strategic management research in the hospitality management field: A co-citation analysis. International Journal of Hospitality Management, 78, 234-250. https://doi.org/10.1016/j.ijhm.2018.09.006

Kuhn, T. S. (1996). The structure of scientific revolutions ( $3^{\text {rd }}$ ed.). The University of Chicago Press.

Laband, D. N., \& Tollison, R. D. (2000). Intellectual collaboration. Journal of Political Economy, 108(3), 632-662. https://doi.org/10.1086/262132

Makkonen, T., \& Mitze, T. (2016). Scientific collaboration between "old" and "new" member states: Did joining the European Union make a difference? Scientometrics, 106(3), 1193-1215. https://doi.org/10.1007/s11192-015-1824-y

March, J. G. (2005). Parochialism in the Evolution of a Research Community: The case of organization studies. Management and Organization Review, 1(01), 5-22. https://doi.org/10.1111/j.17408784.2004.00002.x

Marshakova-Shaikevich, I. V. (2010). Scientific collaboration between Russia and the EU countries: A bibliometric analysis. Herald of the Russian Academy of Sciences, 80(1), 57-62.

https://doi.org/10.1134/S1019331610010077 
Merigó, J. M., Rocafort, A., \& Aznar-Alarcón, J. P. (2016). Bibliometric overview of business \& economics research. Journal of Business Economics and Management, 17(3), 397-413. https://doi.org/10.3846/16111699.2013.807868

Moody, J. (2004). The structure of a social science collaboration network: Disciplinary cohesion from 1963 to 1999. American Sociological Review, 69(2), 213-238. https://doi.org/10.1177/000312240406900204

Mosey, S., Wright, M., \& Clarysse, B. (2012). Transforming traditional university structures for the knowledge economy through multidisciplinary institutes. Cambridge Journal of Economics, 36(3), 587-607. https://doi.org/10.1093/cje/bes008

Nerur, S., Rasheed, A. A., \& Pandey, A. (2016). Citation footprints on the sands of time: An analysis of idea migrations in strategic management. Strategic Management Journal, 37(6), 1065-1084. https://doi.org/10.1002/smj.2377

Nerur, S., Rasheed, A., \& Natarajan, V. (2008). The intellectual structure of the strategic management field: An author co-citation analysis. Strategic Management Journal, 29(3), 319-336. https://doi.org/10.1002/smj.659

Organisation for Economic Co-operation and Development. (2001). Central and Eastern European Countries (CEECS). Retrieved 10 February, 2020 from https://web.archive.org/web/20200210190305/ https://stats.oecd.org/glossary/detail.asp?ID=303

Phelan, S. E., Ferreira, M., \& Salvador, R. (2002). The first twenty years of the strategic management journal. Strategic Management Journal, 23(12), 1161-1168. https://doi.org/10.1002/smj.268

Ramos-Rodríguez, A.-R., \& Ruíz-Navarro, J. (2004). Changes in the intellectual structure of strategic management research: A bibliometric study of the Strategic Management Journal, 1980-2000. Strategic Management Journal, 25(10), 981-1004. https://doi.org/10.1002/smj.397

Ronda-Pupo, G. A., \& Guerras-Martín, L. Á. (2010). Dynamics of the scientific community network within the strategic management field through the Strategic Management Journal 1980-2009: The role of cooperation. Scientometrics, 85(3), 821-848. https://doi.org/10.1007/s11192-010-0287-4

Schendel, D., \& Hofer, C. W. (Eds.). (1979). Strategic management: A New view of business policy and planning. Little Brown.

Stone, M. (1974). Cross-validatory choice and assessment of statistical predictions. Journal of the Royal Statistical Society: Series B (Methodological), 36(2), 111-133. https://doi.org/10.1111/j.2517-6161.1974.tb00994.x

Tan, C. N. L. (2016). Enhancing knowledge sharing and research collaboration among academics: The role of knowledge management. Higher Education, 71(4), 525-556. https://doi.org/10.1007/s10734-015-9922-6

Tan, L., \& Ding, J. (2015). The frontier and evolution of the strategic management theory: A scientometric analysis of Strategic Management Journal, 2001-2012. Nankai Business Review International, 6(1), 20-41. https://doi.org/10.1108/NBRI-09-2014-0036

van der Loo, M. P. J. (2014). The stringdist package for approximate string matching. R Journal, 6(1), 111-122. https://doi.org/10.32614/RJ-2014-011

van Eck, N. J., \& Waltman, L. (2010). Software survey: VOSviewer, a computer program for bibliometric mapping. Scientometrics, 84(2), 523-538. https://doi.org/10.1007/s11192-009-0146-3

Vedres, B. (2017). Forbidden triads and creative success in jazz: The Miles Davis factor. Applied Network Science, 2(1), 31. https://doi.org/10.1007/s41109-017-0051-2

Wagner, C. S., \& Leydesdorff, L. (2005a). Mapping the network of global science: Comparing international co-authorships from 1990 to 2000. International Journal of Technology and Globalisation, 1(2), 185-208. https://doi.org/10.1504/IJTG.2005.007050

Wagner, C. S., \& Leydesdorff, L. (2005b). Network structure, self-organization, and the growth of international collaboration in science. Research Policy, 34(10), 1608-1618.

https://doi.org/10.1016/j.respol.2005.08.002 
White, G. O., Guldiken, O., Hemphill, T. A., He, W., \& Sharifi Khoobdeh, M. (2016). Trends in International strategic management research from 2000 to 2013: Text Mining and bibliometric analyses. Management International Review, 56(1), 35-65. https://doi.org/10.1007/s11575-015-0260-9

Wickham, H. (2016). ggplot2: Elegant graphics for data analysis ( $2^{\text {nd }}$ ed.). Springer. https://doi.org/10.1007/978-3-319-24277-4

Wickham, H. (2018). stringr: Simple, consistent wrappers for common string operations. Retrieved 10 October, 2019 from https://cran.r-project.org/package=stringr

Windley, B. F., Berentsen, W. H., Poulsen, T. M., \& East, W. G. (2019). Europe. In Encyclopaedia Britannica. 